\title{
Statistical Optimization of Medium Components by Response Surface Methodology for Enhanced Production of Bacterial Cellulose by Gluconacetobacter persimmonis
}

\author{
Swati Hegde, Gururaj Bhadri, Kavita Narsapur, Shanta Koppal, Princy Oswal, Naina Turmuri, Veena Jumnal, Basavaraj Hungund* \\ B.V.B College of Engineering \& Technology, Hubli-580031, Karnataka, India
}

\begin{abstract}
Bacterial cellulose has been found to be attractive for novel applications due to its material properties. An optimization of the medium used for the production of bacterial cellulose using Gluconacetobacter persimmonis was carried out. Plackett-Burman (PB) Design for screening of the medium constituents and a Central Composite Design (CCD) for optimization of significant factors were employed. Glucose, yeast extract and peptone were estimated as significant factors from PB design. Bacterial cellulose concentration of $1.72 \%(\mathrm{w} / \mathrm{v})$ was obtained in the medium optimized using CCD method as compared to un-optimized medium that yielded $0.318 \%(\mathrm{w} / \mathrm{v})$. Hence a 6 fold increase was observed after the optimization of medium was carried out. The combined effects of medium components and their optimum regions are reported in this paper.
\end{abstract}

Keywords: Gluconacetobacter persimmonis; Bacterial Cellulose; Plackett Burman Design; Central Composite Design

\section{Introduction}

Cellulose is the most abundant earth biopolymer, recognized as the major component of plant biomass and a representative of microbial extracellular polymers. Efficient producers of cellulose are members of acetic acid bacterium Gluconacetobacter (earlier known as genus Acetobacter). Bacterial cellulose from Acetobacter strains displays unique physical, chemical and mechanical properties including high crystallinity, high water holding capacity, large surface area, elasticity, mechanical strength and biocompatibility [1]. Although bacterial cellulose finds applications in several fields, productivity of cellulose production needs to be addressed so as to make it economically compatible. Hence it becomes necessary to optimize the yields of cellulose production by the use of process improvement strategies. Various workers have optimized medium constituents and process parameters for increased bacterial cellulose (BC) yield [2-6].

Optimization of processing parameters plays an important role in the development of any process owing to their impact on the economy and efficacy of the process. Designing an appropriate production medium and conditions is of crucial importance to improve the efficiency and productivity of bioactive microbial metabolites fermentation process, because it can significantly affect product concentration, yield, and the ease and cost of downstream product separation. Statistically based experimental designs have proved to be more efficient than one-at-atime method, which is complicated and time-consuming, especially on multi-variables screening, and do not consider the complex interactions among different variables. On the other hand, statistical experimental designs provide a systematic and efficient plan for experimentation to achieve certain goals so that many factors can be simultaneously studied. Therefore, in recent years number of statistical designs were used to search the key factors rapidly from a multivariable system, such as Plackett-Burman design and response surface methodology $[2,3,5,7$ 9] because statistical optimization not only allows quick screening of large experimental domain, but also reflects the role of each of the components and their interactions.

Plackett-Burman design allows the evaluation of $(n-1)$ variables by $\mathrm{n}$ experiments; $\mathrm{n}$ must be multiple of 4 ex: 4,8,12 etc. Any factor not assigned to a variable can be designated as dummy variable. The incorporation of dummy variables into experiments makes it possible to estimate the variances of an effect (experimental error). The effect of dummy variables is calculated in the same way as the experimental variables. If there is no interaction and no error in measuring the response, the effect shown by dummy variable should be zero .If the effect is not equal to zero, it is assumed to be a measure of analytical error in measuring the response. This procedure will identify the important variables and allow them to be ranked in order of importance to decide which to investigate in a more detailed study to determine the optimum value to use.

Response Surface Methodology (RSM) is a collection of statistical and mathematical techniques useful for designing experiments, building models, evaluating the effects of factors, and searching optimum conditions of factors for desirable responses [5]. It also has important applications in design, development and formulation of new products as well as in improvement of existing product designs. Statistical experimental design minimizes the error in determining the effect of parameters and it shows the simultaneous, systematic, and efficient variation of all parameters. Response Surface Methodology (RSM) is an effective tool for optimizing the process condition that uses quantitative data from an appropriate experimental design to determine and simultaneously solve multivariate equations [2]. It usually involves an experimental design such as Central Composite Design (CCD) to fit a second-order polynomial by a least squares technique. An equation is used to describe the test variables, and describe the combined effect of all the test variables in the response.

*Corresponding author: Basavaraj Hungund, B.V.B College of Engineering \& Technology, Hubli-580031, Karnataka, India, Tel: 91-9449169349; Fax: 91836-2374985; Email: hungundb@gmail.com

Received December 04, 2013; Accepted December 23, 2013; Published December 30, 2013

Citation: Hegde S, Bhadri G, Narsapur K, Koppal S, Oswal P, et al. (2013) Statistical Optimization of Medium Components by Response Surface Methodology for Enhanced Production of Bacterial Cellulose by Gluconacetobacter persimmonis. J Bioprocess Biotech 4: 142 doi: 10.4172/2155-9821.1000142

Copyright: $\odot 2013$ Hegde S, et al. This is an open-access article distributed under the terms of the Creative Commons Attribution License, which permits unrestricted use, distribution, and reproduction in any medium, provided the original author and source are credited. 
Citation: Hegde S, Bhadri G, Narsapur K, Koppal S, Oswal P, et al. (2013) Statistical Optimization of Medium Components by Response Surface Methodology for Enhanced Production of Bacterial Cellulose by Gluconacetobacter persimmonis. J Bioprocess Biotech 4: 142 doi: 10.4172/2155-9821.1000142

Page 2 of 5

The objectives of the present investigation includes optimization of BC production from G. persimmonis $\mathrm{GH}-2$ by RSM and to study the interrelationship among the media ingredients on BC yield using response surface plots. The medium ingredients were screened by Plackett-Burman (PB) Design and optimization of significant factors was done applying a Central Composite Design (CCD). We observed a 6 fold increase in cellulose yield as an optimum response of the study.

\section{Materials and methods}

\section{Microorganism}

Cellulose producing Gluconacetobacter persimmonis reported earlier was used in this study [10]. The culture was maintained on HS agar slants, transferred and stored at a temperature of $2 \mathrm{oC}-8 \mathrm{oC}$ in the refrigerator.

\section{Culture media and growth conditions}

Standard Hestrin-Schramm (HS) medium containing 2.0\% D-glucose, $0.5 \%$ peptone, $0.5 \%$ yeast extract, $0.15 \%$ citrate and $0.3 \%$ disodium phosphate ( $\mathrm{pH}$ 5.5-6.0) was used in the study [11]. A volume $(100 \mathrm{ml})$ of medium in $250 \mathrm{ml}$ conical flask was inoculated with bacterium and incubated at room temperature for 14 days under stationary conditions to observe the cellulose pellicles that would form at air-liquid interface.

\section{Quantification of bacterial cellulose}

Quantification of cellulose was carried-out as reported in our earlier study [10]. The cellulose pellicles obtained after 14 days of incubation were subjected to filtration to remove excess media and the pellicles were retained in flasks. A solution of $2 \% \mathrm{NaOH}$ was added to the pellicles and boiled for $15 \mathrm{~min}$. The mixture was then filtered and dried in hot air oven at $750 \mathrm{C}$ for $6 \mathrm{~h}$ and dry weight of pellicle was taken to find out the yield.

\section{Screening of the independent variables-Placket Burman Design}

The concentrations of medium components like glucose, yeast extract, peptone, citric acid and disodium phosphate were varied from high to low concentrations (Table 1) and 16 experimental trials were conducted in two batches their effects on $\mathrm{BC}$ production was determined. Trials for 16 sets of media with different concentrations of media components were inoculated with $2 \mathrm{ml}$ of Gluconacetobacter persimmonis culture and were incubated at room temperature for 14 days under static condition of growth [12].

\section{Optimization of the independent variables- Response surface methodology}

To optimize carbon source (glucose), nitrogen source (yeast extract and peptone), a Central Composite Design (CCD), consisting of a set of 20 experiments with replicates at central point was conducted. A three factor 5 level CCD with 20 experiments was used. Trial for

\begin{tabular}{|c|c|c|}
\hline Components & $\begin{array}{c}\text { High concentration } \\
(\% \mathbf{w} / \mathbf{v})\end{array}$ & $\begin{array}{c}\text { Low } \\
\text { concentration(\%w/v) }\end{array}$ \\
\hline Glucose $\left(\mathrm{X}_{1}\right)$ & 4 & 2 \\
\hline Peptone $\left(\mathrm{X}_{2}\right)$ & 1 & 0.5 \\
\hline Yeast extract $\left(\mathrm{X}_{3}\right)$ & 1 & 0.5 \\
\hline Disodium phosphate $\left(\mathrm{X}_{4}\right)$ & 0.6 & 0.3 \\
\hline Citric acid $\left(\mathrm{X}_{5}\right)$ & 0.3 & 0.15 \\
\hline
\end{tabular}

Table 1: Components of HS medium and their high and low concentrations.
20 sets of media with different concentrations of media components were inoculated with $2 \mathrm{ml}$ of Gluconacetobacter persimmonis and were incubated at room temperature for 14 days under static condition of growth.

The following second-order polynomial equation was adopted to study the effects of variables to the response.

$\mathrm{Y}=\beta_{\mathrm{o}}+\beta_{1} \mathrm{X}_{1}+\beta_{2} \mathrm{X}_{2}+\beta_{3} \mathrm{X}_{3}+\beta_{11} \mathrm{X}_{12}+\beta_{22} \mathrm{X}_{22}+\beta_{33} \mathrm{X}_{32}+\beta_{12} \mathrm{X}_{1} \mathrm{X}_{2}+$ $\beta_{23} X_{2} X_{3}+\beta_{13} X_{1} X_{3}(1)$

Where $\mathrm{Y}$ is the response (Cellulose yield, $\mathrm{g} / \mathrm{l}$ ), $\beta_{\mathrm{o}}$ is the constant term, $\beta_{1}, \beta_{2}, \beta_{3}$ the coefficients of linear terms and $\beta_{11}, \beta_{22}, \beta_{33}$ are the coefficients of quadratic terms and $\beta_{12}, \beta_{23}, \beta_{13}$ are the coefficients of cross product terms, $X_{1}, X_{2}$ and $X_{3}$ represent the factors glucose, yeast extract and peptone respectively.

\section{Results and Discussion}

\section{Screening of the independent variables: Plackett-Burman design}

From the Main effects plot (Figure 1) and Pareto chart (Figure 2) of standardized effects, it can be seen that nitrogen sources like peptone and yeast extract and carbon source glucose have significant effect on $\mathrm{BC}$ production when compared to disodium phosphate and citric acid. Yeast extract gave higher yield at its higher concentration $(0.4 \%)$, yield obtained using peptone was found to be greater at its lower concentration $(0.35 \%)$ and yield from glucose is highest at its higher concentration $(0.35 \%)$. Hence it can be inferred that yeast extract is the best nitrogen source for cellulose production by Gluconacetobacter persimmonis. The analysis of yield using PB design is shown in Table 2. This is because Yeast extract contains abundant nitrogen compounds as well as many growth factors and its addition into medium might have stimulated cellulose production. In this investigation the maximum yield was $0.604 \%$ for a medium composition in which the concentrations of yeast extract and peptone were high and minimum yield was $0.0095 \%$ for a medium with low concentration of these nitrogen sources. Hence to optimize $\mathrm{BC}$ production it is necessary to optimize the concentrations of yeast extract, glucose and peptone using different concentrations whereas other components of the medium can be kept constant.

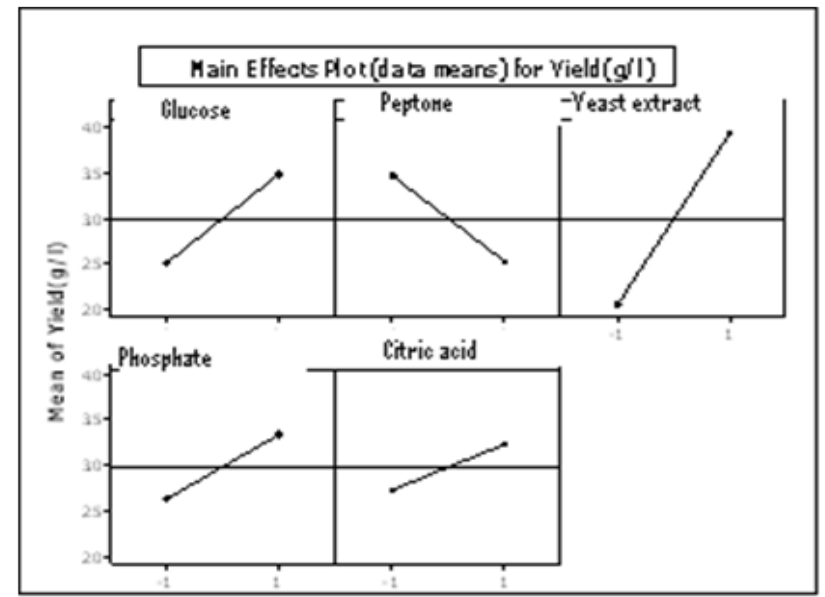

Figure 1: Main effect plot for the screening of medium components using PB design. 
Citation: Hegde S, Bhadri G, Narsapur K, Koppal S, Oswal P, et al. (2013) Statistical Optimization of Medium Components by Response Surface Methodology for Enhanced Production of Bacterial Cellulose by Gluconacetobacter persimmonis. J Bioprocess Biotech 4: 142 doi: 10.4172/2155-9821.1000142

Page 3 of 5

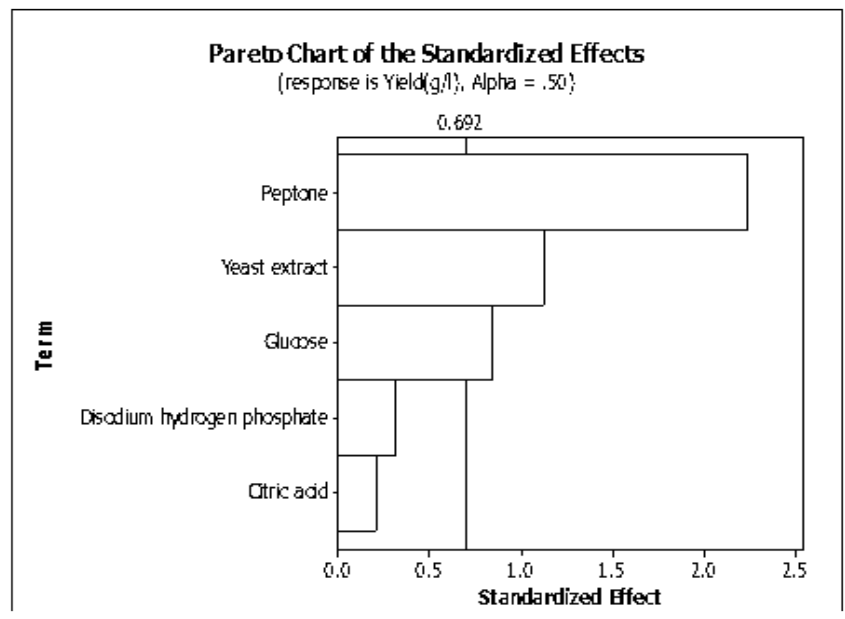

Figure 2: Pareto chart of the standardized effects showing effect of medium constituents on cellulose yield.

\begin{tabular}{|c|c|l|l|l|c|}
\hline \multirow{2}{*}{$\sum(\mathrm{H})$} & Glucose & Peptone & Yeast & phosphate & Citric acid \\
\cline { 2 - 6 } & 34.73 & 33.15 & 32.79 & 31.3 & 24.48 \\
\hline$\sum(\mathrm{L})$ & 25.10 & 26.68 & 2.042 & 32.027 & 35.35 \\
\hline Difference & 9.63 & 6.47 & +5.75 & -0.72 & -10.9 \\
\hline Effect & 1.2035 & 0.8085 & 0.0185 & -0.09 & -1.36 \\
\hline Mean square & 7.059 & 2.614 & 2.06 & 0.033 & 1.37 \\
\hline
\end{tabular}

Table 2: Analysis of cellulose yield by Gluconacetobacter persimmonis.

\section{Optimization of the independent variables: Response surface methodology}

To optimize carbon (glucose) and nitrogen (yeast extract and peptone) sources, a Central Composite Design consisting of a set of 20 experiments with six replicates at central point was conducted. Table 3 shows variables and their levels for central composite design (CCD). The CCD matrix of the independent variables in coded units (experimental design) along with predicted and experimental values of response is given in Table 4 . All the experiments were performed in 250 $\mathrm{ml}$ Erlenmeyer flask containing $100 \mathrm{ml}$ of media. The quadratic model expressed by equation (2) represents cellulose yield (Y) as a function of glucose $\left(\mathrm{X}_{1}\right)$, peptone $\left(\mathrm{X}_{2}\right)$ and yeast extract $\left(\mathrm{X}_{3}\right)$.

The response equation from the above set of experiments can be written as

$\mathrm{Y}=0.467+0.123 \mathrm{X}_{1}+0.01 \mathrm{X}_{2}+0.267 \mathrm{X}_{3}+0.031 \mathrm{X}_{1}^{2}+0.054 \mathrm{X}_{2}^{2}+$ $0.319 \mathrm{X}_{3}^{2}-0.282 \mathrm{X}_{1} \mathrm{X}_{2}+0.326 \mathrm{X}_{1} \mathrm{X}_{3}-0.224 \mathrm{X}_{2} \mathrm{X}_{3}(2)$

The statistical significance of the polynomial equation was checked by $\mathrm{P}$ test and Analysis Of Variance (ANOVA) for response surface quadratic model is given in Table 5. The $\mathrm{P}$ value coeffiecient for $\mathrm{X}_{1} \mathrm{X}_{2}$ and $\mathrm{X}_{1} \mathrm{X}_{3}$ was 0.028 and 0.014 respectively indicating the significant interaction between two variables $\mathrm{X}_{1}$ and $\mathrm{X}_{2}$ as well as between $\mathrm{X}_{1}$ and $\mathrm{X}_{3}$.

The estimated coefficients for BC yield are presented in Table 6. The significance of each coefficient was determined by student's T-test and $\mathrm{P}$ values. The larger the magnitude of $\mathrm{T}$-value and smaller $\mathrm{P}$ value, the more significant is the corresponding coefficient. This means that quadratic main effects of glucose, yeast extract and peptone are more significant. The response obtained under different combinations of variables and defined experimental design Table 2 were analyzed using the Analysis of Variance (ANOVA) appropriate to the experimental

\begin{tabular}{|c|c|c|c|c|c|c|}
\hline Variable & Symbols & -1.68179 & -1 & 0 & 1 & 1.68179 \\
\hline Glucose (\%) & $\mathrm{X}_{1}$ & 1.31821 & 2 & 3 & 4 & 4.68179 \\
\hline Yeast extract (\%) & $\mathrm{X}_{2}$ & 0.3295 & 0.5 & 0.75 & 1 & 1.1704 \\
\hline Peptone (\%) & $\mathrm{X}_{3}$ & 0.3295 & 0.5 & 0.75 & 1 & 1.1704 \\
\hline
\end{tabular}

Table 3: Variables and their levels for CCD.

\begin{tabular}{|c|c|c|c|c|c|}
\hline $\begin{array}{c}\text { Experiment } \\
\text { No }\end{array}$ & Glucose & Yeast extract & Peptone & $\begin{array}{c}\text { Observed } \\
\text { yield(\% w/v) }\end{array}$ & $\begin{array}{c}\text { Predicted } \\
\text { yield(\%w/v) }\end{array}$ \\
\hline 1 & 0.00000 & 0.00000 & 0.00000 & 0.4657 & 0.467 \\
\hline 2 & 0.00000 & 0.00000 & 0.00000 & 0.3749 & 0.467 \\
\hline 3 & 0.00000 & 0.00000 & 1.68179 & 1.6943 & 1.818 \\
\hline 4 & 1.00000 & 1.00000 & -1.00000 & 0.5189 & 0.354 \\
\hline 5 & 1.00000 & 1.00000 & 1.00000 & 1.4262 & 1.091 \\
\hline 6 & -1.00000 & -1.00000 & -1.00000 & 0.3011 & 0.293 \\
\hline 7 & 0.00000 & -1.68179 & 0.00000 & 0.5024 & 0.602 \\
\hline 8 & 1.00000 & -1.00000 & 1.00000 & 1.0271 & 1.082 \\
\hline 9 & -1.68179 & 0.00000 & 0.00000 & 0.1493 & 0.348 \\
\hline 10 & 0.00000 & 0.00000 & 0.00000 & 0.5319 & 0.467 \\
\hline 11 & -1.00000 & -1.00000 & 1.00000 & 0.7986 & 0.620 \\
\hline 12 & 1.00000 & -1.00000 & -1.00000 & 0.7654 & 0.450 \\
\hline 13 & -1.00000 & 1.00000 & -1.00000 & 1.7216 & 1.323 \\
\hline 14 & 0.00000 & 0.00000 & -1.68179 & 0.5605 & 0.922 \\
\hline 15 & 0.00000 & 0.00000 & 0.00000 & 0.6701 & 0.467 \\
\hline 16 & 1.68179 & 0.00000 & 0.00000 & 0.4751 & 0.762 \\
\hline 17 & 0.00000 & 0.00000 & 0.00000 & 0.2657 & 0.467 \\
\hline 18 & 0.00000 & 1.68179 & 0.00000 & 0.2495 & 0.635 \\
\hline 19 & -1.00000 & 1.00000 & 1.00000 & 0.7846 & 0.756 \\
\hline 20 & 0.00000 & 0.00000 & 0.00000 & 0.5762 & 0.467 \\
\hline
\end{tabular}

Table 4: Experimental design, predicted and observed yields in CCD experiments in term of cellulose yield.

\begin{tabular}{|c|c|c|c|c|c|c|}
\hline Source & df & Seq SS & Adj SS & Adj MS & F value & P \\
\hline Regression & 9 & 4.5391 & 4.5391 & 0.50434 & 5.22 & 0.08 \\
\hline Linear & 3 & 1.1761 & 1.1761 & 0.39203 & 4.05 & 0.040 \\
\hline Square & 3 & 1.4774 & 1.4774 & 0.49247 & 5.09 & 0.021 \\
\hline Interaction & 3 & 1.8856 & 1.8856 & 0.62852 & 6.50 & 0.010 \\
\hline Residual error & 10 & 0.9669 & 0.9669 & 0.09669 & & \\
\hline Pure error & 5 & 0.1053 & 0.1053 & 0.02105 & & \\
\hline Total & 19 & 5.5060 & & & & \\
\hline
\end{tabular}

Table 5: Analysis of variance.

\begin{tabular}{|c|c|c|c|c|}
\hline Term & Coefficient & Standard error & t-value & $\mathbf{P}$ \\
\hline Constant & 0.466859 & 0.12682 & 3.681 & 0.004 \\
\hline Glucose & 0.122988 & 0.08414 & 1.462 & 0.175 \\
\hline Yeast extract (YE) & 0.009795 & 0.08414 & 0.116 & 0.910 \\
\hline Peptone & 0.266263 & 0.08414 & 3.164 & 0.010 \\
\hline Glucose*Glucose & 0.031192 & 0.08191 & 0.381 & 0.711 \\
\hline YE*YE & 0.05371 & 0.08191 & 0.656 & 0.527 \\
\hline Peptone*Peptone & 0.319409 & 0.08191 & 3.899 & 0.003 \\
\hline Glucose*YE & -0.281738 & 0.10994 & -2.563 & 0.028 \\
\hline Glucose*Peptone & 0.326062 & 0.10994 & 2.966 & 0.014 \\
\hline YE*Peptone & -0.223613 & 0.10994 & -2.034 & 0.069 \\
\hline
\end{tabular}

Estimated regression coefficients representing response and the variable. $\mathrm{S}=0.3110 \quad \mathrm{R}-\mathrm{Sq}=82.4 \% \quad \mathrm{R}-\mathrm{Sq}(\mathrm{adj})=66.6 \%$

Table 6: Estimated regression coefficients representing response and the variable.

design Table 4 which indicated that the sum of squares due to regression (first and second-order terms) was found to be significant $(\mathrm{p}<0.05)$ and lack of fit was not significant. The value of coefficient of determination $\left(\mathrm{R}^{2}=0.824\right)$ suggested that the model is a good fit though not accurate. The $\mathrm{R}^{2}$ is the proportion of variability in response values explained or 
Citation: Hegde S, Bhadri G, Narsapur K, Koppal S, Oswal P, et al. (2013) Statistical Optimization of Medium Components by Response Surface Methodology for Enhanced Production of Bacterial Cellulose by Gluconacetobacter persimmonis. J Bioprocess Biotech 4: 142 doi: 10.4172/2155-9821.1000142

Page 4 of 5

accounted for by the model. The value of $\mathrm{R}^{2}$ is always in between 0.0 and $1.0 \mathrm{R}^{2}$ value close to 1.0 implies that the model is accurate and predicts better response. However, model with higher $\mathrm{R}^{2}$ value always does not mean that model is accurate. Large $\mathrm{R}^{2}$ value also is resulted by addition of non-significant extra variables in the model. Thus, it may be possible of a model having higher $\mathrm{R}^{2}$ value with poor prediction of response. So the term adjusted $\mathrm{R}^{2}$ has been introduced which arranges the $\mathrm{R}^{2}$ values for the sample size and for the number of variables in the model. Addition of insignificant model term in the model leads to decrease in adjusted $\mathrm{R}^{2}$ value. So, the value of $\mathrm{R}^{2}$ should be as close as that of adjusted $\mathrm{R}^{2}$.

Parity plot (Figure 3) showed the distribution of experimental and model predicted values where data points are localized close to the diagonal line suggesting the model is adequate enough to explain cellulose production. The 3D plot (Figure 4 ) and their respective 2D contour plots (Figure 5) provide a visual interpretation of the interaction between two factors. In the response surface plot, glucose is held at an intermediate level and levels of peptone and yeast extract are varied from -1.5 to +1.5 . It can be seen that the cellulose yield increases with increase in concentration of peptone and with decrease in concentration of yeast extract. The corresponding Contour plots indicate difeerent regions of yields based on different colours. The maximum yield falls in the range $2-2.5 \mathrm{~g} / 100 \mathrm{ml}$ as indicated by dark shaded region in the plot. Hence to optimize the levels of peptone and yeast extract, it is

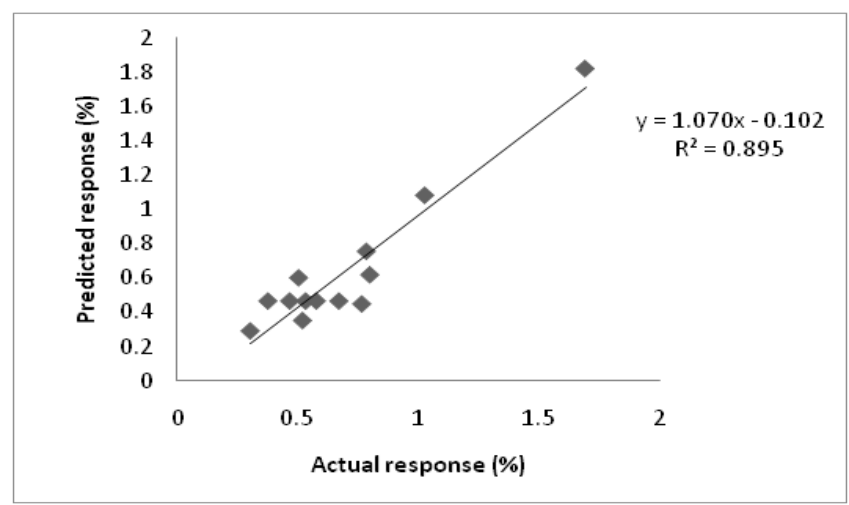

Figure 3: Parity plot showing distribution of experimental and predicted values of cellulose production ( $\% \mathrm{w} / \mathrm{v})$. necessary to carry out experiments in this region of higher yield. So the levels of peptone has to be varied between 1.4 to 1.618 and yeast extract has to be varied from -1.5 to -0.5 to optimize BC production. The graphs also show that the yield of cellulose increases with increase in concentrations of peptone and glucose. The yield is found to decrease with decrease in concentrations of glucose and peptone. The Contour plot shows different ranges of yields. To get optimum conditions the experiments have to be done in the region of maximum yield and the levels of glucose and peptone have to be varied from 1 to 1.6 and 1.5 to 1.68 respectively.

From Figure 5, it can be observed that with increase in concentration of yeast extract and with decrease in concentration of glucose, the yield of cellulose increases considerably. The contour plot indicates the levels of yeast extract and glucose that have to be used to get optimum conditions as 1 to 1.6 for yeast extract and -1.5 to -0.5 for glucose.

In the previous studies for optimization for $\mathrm{BC}$ production, Embuscado et. al., [2] used five-level, four factor central composite design. They found all four factors affected cellulose yield significantly from G. xylinus. This is in line with present investigation. However, Rani et. al., [5] optimized cultural conditions for BC production from G. hansenii by central composite design. They used coffee cherry husk and corn steep liquor as less expensive sources of carbon and nitrogen sources respectively. Casarica et. al., [6] brought about improvement in BC yield using poor quality horticulture substrates using Taguchi method. In the study carried-out by Bae and Shoda [3], culture conditions in a jar fermenter for $\mathrm{BC}$ production were optimized using Box-Behnken design, Response surface methodology was used to predict the levels of various factors.

\section{Conclusion}

This work has demonstrated the use of Central composite design by determining the conditions which are required to get optimum yield of cellulose production from $G$ persimmonis. This methodology could therefore be successfully employed to process development where an analysis of effects and interactions of many experimental factors are required. Central composite experimental design maximizes the amount of information that can be obtained, while limiting the numbers of individual experiments required. Response curves are very helpful in visualizing the main effects and interaction of factors. Thus smaller and less time consuming experimental designs could generally suffice for the optimization of many processes. From the above Main effects plot and Pareto chart of standardized effects, it can be seen that

\section{Surface plots of yields $[\%]$ vs glucose. peptone}

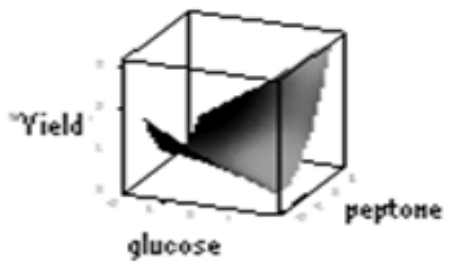

(a)

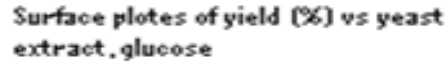

extract, glucase

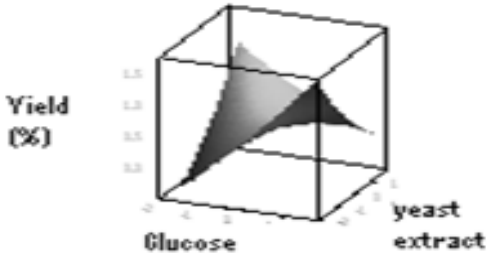

(b)
Surface plot of yield (\%) ws peptone, yeast extract

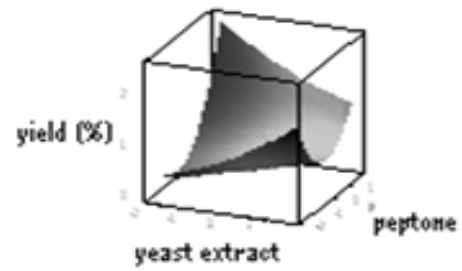

(c)

Figure 4 (a-c): Surface plot and contour plots of showing the interaction effects. While the plots show interaction of two factors, third factor is held constant at its middle value. 
Citation: Hegde S, Bhadri G, Narsapur K, Koppal S, Oswal P, et al. (2013) Statistical Optimization of Medium Components by Response Surface Methodology for Enhanced Production of Bacterial Cellulose by Gluconacetobacter persimmonis. J Bioprocess Biotech 4: 142 doi: 10.4172/2155-9821.1000142

\section{Contur Plot f Yidd(g 100-1) vs Peptene, Yestertract}

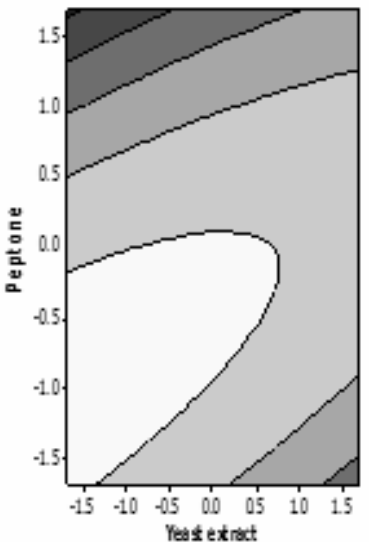

Contur Plot of Yiedg/ $/ 100 \mathrm{~m})$ vs Peptone, Glucose
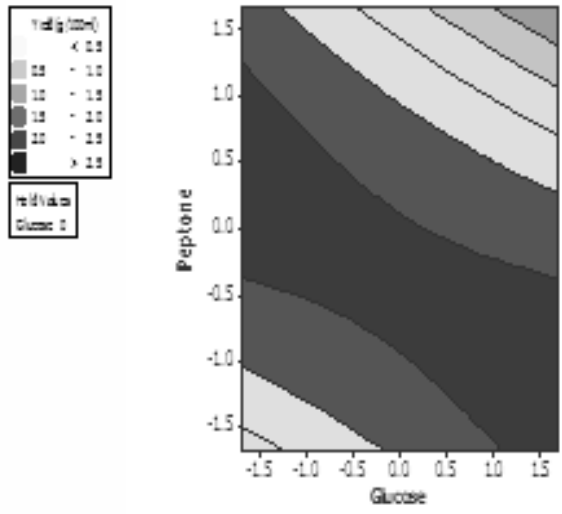

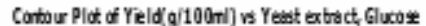
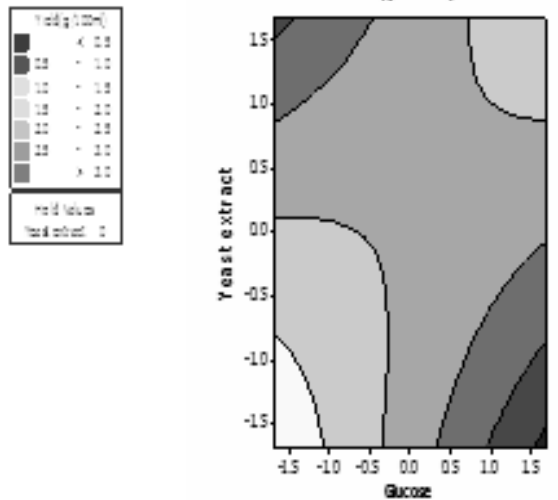

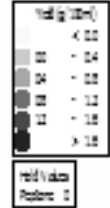

Figure 5 (a-c): Contour graphs showing the interaction between factors

nitrogen sources like peptone and yeast extract and carbon source glucose have significant effect on BC production when compared to disodium phosphate and citric acid. Hence to optimize BC production it is necessary to optimize the concentrations of yeast extract, glucose and peptone using different concentrations whereas other components of the medium can be kept constant. Hence statistical experimental designs are powerful tools for the rapid search of key factors from a multivariable system and minimizing the error in determining the effect of parameters and the results are achieved in an economical manner.

\section{Acknowledgement}

The authors acknowledge $\mathrm{Dr}$. Ashok Shettar, Principal, BVBCET for providing the facilities. The authors also acknowledge Dr. B.B Kotturshettar and Dr. V.N Gaitonde for their technical help during the studies.

\section{References}

1. Yoshinaga F, Tonouchi N, Watanabe K (1997) Research Progress in Production of Bacterial Cellulose by Aeration and Culture and its Applications as New Industrial Material. Biosci Biotechnol Biochem 61: 219-224.

2. Embuscado ME, Marks JS, BeMiller NB (1994) Bacterial Cellulose. II. Optimization of Cellulose Production by Acetobacter Xylinum through Response Surface Methodology. Food Hydrocoll 8: 419-430.

3. Bae S, Shoda M (2005) Statistical Optimization of Culture Conditions for Bacterial Cellulose Production using Box-Behnken Design. Biotechnol Bioengg 90: 20-28.

4. Hungund BS, Gupta SG (2010) Production of Bacterial Cellulose from Enterobacter Amnigenus GH-1 Isolated from Rotten Apple. World J Microb Biot 26: $1823-1828$
5. Rani Usha M, Rastogi NK, Appaiah KA (2011) Statistical Optimization of Medium Composition for Bacterial Cellulose Production by Gluconacetobacter Hanenii UAC09 using Coffee Cherry Husk Extract-an Agro Industry Waste. J Microb Biot 21: 739-745.

6. Casarica A, Campeanu G, Moscovici M, Ghiorghita A, Manea V (2011) Improvement of Bacterial Cellulose Production by Acetobacter Xylinum DSMZ2004 on Poor Quality Horticulture Substrates using the Taguchi Method for Media Optimization. Part I. Cellulose Chem Technol 47: 61-68.

7. Vohra A, Satyanarayana T (2002) Statistical Optimization of the Medium Components by Response Surface Methodology to Enhance Phytase Production by Pichia Anomala. Process Biochem 37: 999-1004.

8. Baskar G, Renganathan (2009) Statistical Screening of Process Variables for the Production of L-Asparaginase from Cornflour by Aspergillus Terreus MTCC 1782 in Submerged Fermentation. Indian J Sci Technol 2: 45-48.

9. Vuddaraju SP, Nikku M, Chaduvulu A, Dasari VR, Donthireddy R (2010) Application of Statistical Experimental Designs for the Optimization of Medium Constituents for the Production of L-Asparginase by Serratia Marcescens. J Microbial Biocheml Technol 2: 89-94.

10. Hungund BS, Gupta SG (2010) Improved Production of Bacterial Cellulose from Gluconacetobacter Persimmonis GH-2. J Microbial Biochem Technol 2 127-133.

11. Hestrin S, Schramm M (1954) Synthesis of Cellulose by Acetobacter Xylinum II. Preparation of Freeze-Dried Cells Capable of Polymerizing Glucose to Cellulose. Biochem J 58: 345-352.

12. Son HJ, Heo MS, Kim YG, Lee SJ (2001) Optimization of Fermentation Conditions for the Production of Bacterial Cellulose by a Newly Isolated Acetobacter Sp.A9 in Shaking Cultures. Biotechnol Appl Biochem 33: 1-5. 